\title{
GROUPS DECISION MAKING WITHIN THE ORGANIZATION
}

\author{
Stan Ştefania Anca, Lecturer \\ UNIVERSITY OF BACAU
}

\section{Abstract:}

In a highly global market, organizations that have the ability to analyze and rapidly respond to the constantly changing marketplace will have the greatest chance of remaining competitive and profitable. Group decision making is the process of arriving at a judgment based upon the feedback of multiple individuals. Due to the importance of the group decision making process, decision making models can be used to establish a systematic means of developing effective group decision making. Once a decision has been made, the members of the group should be willing to accept it and support its implementations.

In a highly global market, organizations that have the ability to analyze and rapidly respond to the constantly changing marketplace will have the greatest chance of remaining competitive and profitable. This is greatly dependent upon work teams that are cohesive, flexible, and able to rapidly arrive at important decisions. Group decision making provides for increased ability to gather pertinent information, to develop creative solutions, and to generate new ideas.

The most of the important decisions within organizations are made by groups, or within a group context. Group decision making is the process of arriving at a judgment based upon the feedback of multiple individuals. A group brings more resources to a problem than are available to one person. Through group discussion, group member pool their knowledge. The interaction of group members leads to new ideas and insights that no single member would have developed. Being part of group, encourages members to try to make a good decision and to try to perform better.

Group decision making has many benefits as well as some disadvantages.

Advantages of Group Decisions:

- Group decisions help to combine individual strengths of the group members and hence has a set of varied skill sets applied in the decision making process.

- Individual opinions can be biased or affected with pre-conceives notions are restricted perspectives, group decision help to get a broader perspective owing to differences of perception between individual in the group.

- A group decision always means enhanced collective understanding of the course of action to be taken after the decision is taken.

- A group decision gains greater group commitment since everyone has his/her share in the decision making.

- Group decisions imbibe a strong sense of team spirit amongst the group members and helps the group to think together in terms of success as well as failure.

Disadvantages of Group Decisions:

- One of the major disadvantages of group decision making is that it is more time consuming than the process of individual decision making.

- Group decisions take longer to be finalized since there are many opinions to be considered and valued.

- In case of authoritarian or minority group decision making, the people whose opinions are not considered tend to be left out from the decision making process and hence the team spirit ceases to grow.

- The responsibility and accountability of the decisions are not equally shared in some cases which leads to a split in the group and hence hamper the overall efficiency of the group.

Because the performance of a group involves taking into account the needs and opinions of every group member, being able to come to an equitable decision as efficiently as possible is important for the functioning of the group. There are a variety of ways to 
make decisions as a group; the seven step decision-making model presented below offers an effective structure for choosing an appropriate course of action for a particular task or project.

\section{Identify the decision to be made.}

Before beginning to gather information and list alternatives, it is important for you as a group to understand clearly what you are trying to decide so you have a goal on which to focus your discussions.

\section{Analyze the issue under} discussion. Once you have defined your goal, examine the data and resources that you already have, and identify what additional information you may need.

3. Establish criteria. Identify the criteria or conditions that would determine whether a chosen solution is successful. Ideally, a solution will be feasible, move the group forward, and meet the needs of every group member.

4. Brainstorm potential solutions. Using the resources and information collected above, brainstorm for potential solutions to the problem or decision identified in step 1. This involves collecting as many ideas as possible. At this stage, ideas should not be criticized or evaluated.

5. Evaluate options and select the best one. Once you have a list of potential solutions, you are now ready to evaluate them for the best alternative according to the criteria identified in step 3. Remember that you may be able to combine ideas to create a solution. Ideally, everyone would agree with solution (a consensus), but not everyone may agree. In this case, you will need to use a different decision making methods decisions:

There are several types of group

1. Unilateral - a decision made by one person, often the nominal leader, without consultation with other group members. At times, it can be appropriate. For example, a minor decision that needs to be made right away. If it is repeated and inappropriate, this type of decision can carry a very low group commitment.

2. Handclasp - decisions made by two members. One suggests, the other endorses and carries it through without adequate discussion or group consideration. This type has high commitment for the two who made it, but generally not for the others.

3. Clique - similar to the Handclasp but with more people involved. This type usually occurs when a close sub- group decides what is good for the rest of the group. Repeated clique decisions cause splintering of the group and low commitment.

4. Baiting - a technique that reduces discussions around decisions. A person will say, "Now we are all agreed, right?" and only the very brave will speak up. This usually suppresses obvious dissention and lowers group commitment.

5. Majority Rule - a popular way of making decisions. However, if the outcome of a secret ballot vote would produce any surprises, it is not a good time to make majority rule decisions. What happens is that a sizeable segment of the group may feel devalued and decrease their commitment to the decisions in which they "lose" to the majority vote.

6. Consensus - similar to Majority Rule, but everyone knows that what they think and value is being considered by all, and there will be no surprises if you vote. Each person will agree that, under the circumstances, which may not be ideal, the decision made is a fair and workable one that they can live with and support.

Since the resources involved in the group decision-making process as well as the impact of these decisions affect organizational performance, it is crucial to make the group decision-making process as efficient and effective as possible.

Due to the importance of the group decision making process, decision making models can be used to establish a systematic means of developing effective group decision making. In general, four group decision making models can be identified each possessing distinct advantages and disadvantages. These four models are the rational, political, process, and garbage can models

\section{The Rational Model}

The first model is the rational model. This model is based upon an economic view 
of decision making. It is grounded on goals/objectives, alternatives, consequences and optimality. The model assumes that complete information regarding the decision to be made is available and one correct conception of a problem, or decision to be made can be determined. The model further assumes that the decision-makers consistently assess the advantages and disadvantages of any alternatives with goals and objectives in mind. They then evaluate the consequences of selecting or not selecting each alternative. The alternative that provides the maximum utility (i.e., the optimal choice) will be selected.

\section{The Political Model}

In contrast to the preceding model, in political model, the individuals involved do not accomplish the decision task through rational choice in regard to objectives. The decision makers are motivated by and act on their own needs and perceptions. This process involves a cycle of bargaining among the decision makers in order for each one to try to get his or her perspective to be the one of choice. More specifically, this process involves each decision-maker trying to sway powerful people within the situation to adopt his or her viewpoint and influence the remaining decision-makers .The political model does not involve making full information available or a focus on the optimal viewpoint like that of the rational model . Full information is highly unlikely, since the political model operates based upon negotiation that is often influenced by power and favors. In fact, information is often withheld in order to better maneuver a given perspective. Since information is often withheld and subsequently incomplete, the optimal viewpoint is not a key aspect of this model.

The advantages of the political model remains that it provides a representation of the subjective manner in which the real world often operates, and it can minimize conflict. Individuals will always have their personal biases and agendas that influence their behavior. By identifying or acknowledging this fact in the decision-making process, potential problems and conflict can be foreseen and minimized. Conflict is also minimized by the swaying of powerful people to support a particular viewpoint. Once the powerful people support this perspective, other group members usually fall in line behind them.

\section{The Process Model}

In contrast to the political model, the third basic model of decision making is more structured. This model is the process model. With the process model, decisions are made based upon standard operating procedures, or pre-established guidelines within the organization. Additionally, the organization of past, present, and future events, as well as conformity, are integral parts to this model . The organization of the past, present and future events are important, because they can be used as a consistent foundation for decision making. Considering these time events provides further refinement of the guidelines that help to determine outcomes. Conformity is an integral part of the process model since it is the means by which doubt, or incertitude is dealt with during the decision task. If decision makers are uncertain as to the potential effectiveness or the results of a decision, they conform to the pre-established standard. This conformity should not be construed to mean that the decision will not have a solid foundation. In this case, conformity merely relates to the fact that the reasoning for the decision is based upon predetermined guidelines .

\section{The Garbage Can Model}

The fourth model of decision making is the garbage can model. This model is most appropriate for judgment tasks in organizations where the technologies are not clear, the involvement of participants fluctuates in the amount of time and effort given, and choices are inconsistent and not well defined. In such an organization, an opportunity to make a decision is described as a garbage can into which many types of problems and solutions are dropped independently of each other by decisionmakers as these problems and solutions are generated. The problems, solutions and decision makers are not necessarily related to each other. They move from one decision 
opportunity to another in such a manner that the solutions, the time needed and the problems seem to rely on a chance alignment of components to complete the decision. These components are the combination of options available at a given time, the combination of problems, the combination of solutions needing problems, and the external demands on the decision makers.

Once a decision has been made, the members of the group should be willing to accept it and support its implementations. The primary criteria for evaluating a decision making approach are quality, speed and acceptance or support. The importance of these three criteria varies depending on the problem or situation.

In general, decision - making techniques that include group discussion and participation lead to higher quality decisions. Group decision making is slower than individual decision making but the importance of speed as a criterion varies. Some decisions are important and need to be made quickly, whereas other decisions should be put off until the group gathers more information. The third factor is acceptance. When acceptance is important, groups should use either consensus decision making or a voting approach that requires more than the majority to adopt the decisions.

The eventual success or failure of the group as problem solvers and decision makers depends on the information and knowledge of the participants as well as on their ability to work together effectively during a group decision-making meeting.

\section{References:}

[1] Drucker Peter, Managementul viitorului, Ed. ASAB, Bucureşti, 2004

[2] Fotache Doina, Groupware , Ed. Polirom, Iaşi, 2002

[3] Neculau Adrian, Dinamica grupului şi a echipei, Ed. Polirom, Bucureşti, 2007

[4] West A Michael, Lucrul în echipă, Ed. Polirom, Bucureşti, 2005 